FEB 141964

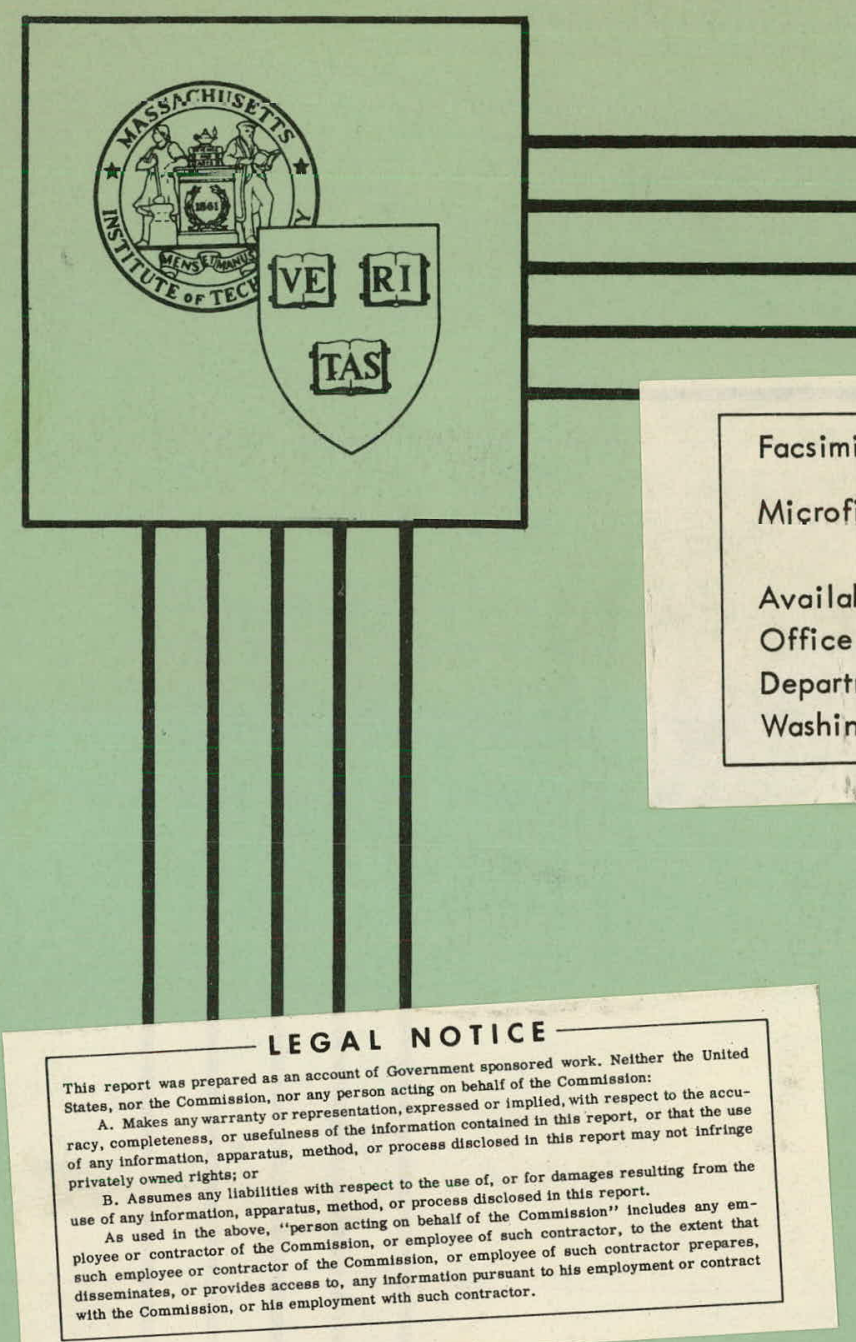

SEMI-ANNUAL REPORT

for the period

JuIy 1 to December 31, 1963

A.E.C. Contract AT(30-1)-2076

M. Stanley Livingston

Director

January 17,1964

\title{
MASSACHUSETTS INSTITUTE OF TECHNOLOGY and HARVARD UNIVERSITY
}

\section{CAMBRIDGE ELECTRON ACCELERATOR}

\section{CAMBRIDGE 38, MASSACHUSETTS}

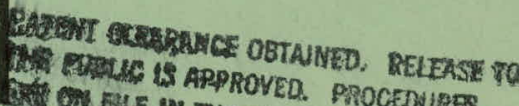

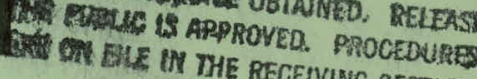

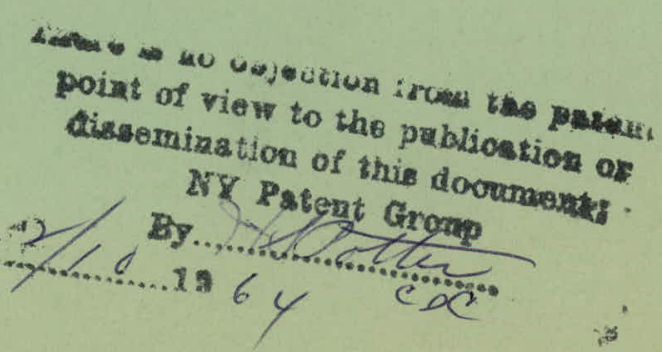




\section{DISCLAIMER}

This report was prepared as an account of work sponsored by an agency of the United States Government. Neither the United States Government nor any agency Thereof, nor any of their employees, makes any warranty, express or implied, or assumes any legal liability or responsibility for the accuracy, completeness, or usefulness of any information, apparatus, product, or process disclosed, or represents that its use would not infringe privately owned rights. Reference herein to any specific commercial product, process, or service by trade name, trademark, manufacturer, or otherwise does not necessarily constitute or imply its endorsement, recommendation, or favoring by the United States Government or any agency thereof. The views and opinions of authors expressed herein do not necessarily state or reflect those of the United States Government or any agency thereof. 


\section{DISCLAIMER}

Portions of this document may be illegible in electronic image products. Images are produced from the best available original document. 
CEAL-1009

\section{SUMMARY}

Part I indicates the scope of the contract, concerned with operation of the 6mBev Cambridge Electron Accelerator. Part II lists the fifteen experiments that were in progress or in advanced stage of preparation during the current six-month period. Part III describes the improvements made in the accelerator and in the supporting facilities. Part IV deals with routine operation of the accelerator, which has been on a five-day three-shift basis. Part V lists several major improvements made, including the new Control Room and the new Counting Room.

The accelerator has been running reasonably well and a large amount of useful data has been obtained by the teams of experimentalists. The need for a better linac is still apparent.

\section{PART I. INTRODUCTION}

This report summarizes the work done under the Harvard-AEC Contract AT(30-1)-2076 during the period July I - December 31, 1963. The contract calls for the operation and maintenance of the CEA 6-billionelectron-volt symchrotron and for designing, procuring, installing, and operating various equipments and facilities pertinent to the experiments to be performed.

Scheduling of research operations is the responsibility of the Director of CEA assisted by a Planning Committee which currently includes Prof. I. Osborne of M.I.T. and Prof. F. Pipkin of Harvard. 
PART II: THE EXPERTIENTS

During the six-month period in question there were fifteen experiments in progress or in advanced stages of preparation. These are described briefly below.

\section{Electron Scattering (R. Wilson et al)}

Physicists from Harvard have obtained a large volume of data on elastic scattering of high energy electrons by protons, with the purpose of determining the electric and magnetic form factors of the proton. In runs made early in 1963 targets of polyethylene and other low-Z solids were used and were mounted directly in the path of the orbiting beam of 1 to $4 \mathrm{Bev}$ electrons; the recoiling proton was detected with the aid of a spectrometer situated in the Target Area; the results were reported in Phys. Rev. Letters of I June 1963. In recent months a liquid hydrogen target, also mounted in the vacuum ring, was employed. The beam energy was 2 to $5.5 \mathrm{Bev}$. The particle detected was the elastically scattered electron. Preliminary results, published in Phys. Rev. Letters of $15 \mathrm{Dec}$. 1963, indicate that the form factors continue to decrease smoothly with increasing energy of the incident electron. In recent months the elastic scattering of electrons by neutrons has been investigated, and also the inelastic scattering of electrons by protons. In runs planned for the near future, the work will be extended to higher energies. 
2. Bubble Chamber Investigations (Cambridge Bubble Chamber Group)

During the current six-month period, physicists from M.I.T., Harvard, and Brown completed the installation and testing of their 12-inch-diameter liquid-hydrogen-fill led bubble chamber and obtained over 100,000. successful photographs, Inspection of the first 20,000 photographs revealed a wealth of interesting events, now being analyzed. The necessary reduction in intensity of the 5 Bev bremsstrahlung beam from the synchrotron target was accomplished by conversion to positron-electron pairs and reconversion of the positrons. The task of assembling the 40-inch liquid-hydrogen-filled bubble chamber, to be enclosed in the 300-ton magnet Colossus, is continuing, and work on the associated cryogenics plant has progressed well. It is expected that the 40-inch chamber will be put into operation in the summer or fall of 1964.

\section{Photoproduction of Mesons (L. Osborne et al)}

Physicists from M.I.T. and neighboring universities obtained a large amount of data on the cross-sections of photoproduction of positive and neutral pions by bremsstrahlung photons having energies of 1 to $6 \mathrm{Bev}$. A liquid hydrogen target was used, and a large spectrometer Moby Dick employing two 12-inch-bore quadrupole magnets, a gas-filled Cerenkov counter, two analyzing magnets Scylla and Charybdis, and a scintillation-counter hodoscope. The data are now being analyzed. Additional runs, some designed to measure 
photoproduction cross-sections of kaons and negative pions, are to be made soon.

4. Wide-Angle Muon Pair Production (R. Weinstein et al)

During the current six-month period, physicists from Northeastern University, M.I.T., and elsewhere made many improvements in their equipment for measuring wide-angle muon pairs produced by high-energy photons. Higher counting rates and higher resolution can now be achieved. Plans have been made for installing the large array of data handling equipment in the new Counting Room. It is expected that, when the apparatus is put into operation in the epring, the validity of quantum electrodynamics at high momentum transfer and short interaction distance can be determined with greater precision than was attainable previously. The data obtained in runs made in the spring of 1963 have been analyzed and a formal report is being prepared.

5. Photoproduction of Pairs with Large Momentum Transfers (V.W. Hughes et al)

Physicists from Yale have set up equipment for measuring the ratio of, and absolute values of, the cross sections for photoproduction of pairs of electrons and muons in a hydrogen target as a function of bremsstrahlung endpoint energy, particle momentum, and production angle. One member of each pair is detected. Analysis is accomplished with the aid of a 60-inch pair spectrometer magnet, two 4-inch-bore focusing (quadrupole) magnets, two differential gas Cerenkov counters, and several scintillation counters. A series of runs is scheduled to start 
in February: some measurements of pion photoproduction will also be made. Results of earlier (June 1963) measurements of pion production have been analyzed and reported in Phys. Rev: Letters for Nov. 15, 1963; they are in qualitative agreement with calculations based on the peripheral model proposed by Drell.

6. Photoproduction of Sigma Particles (R. H. Milburn et al)

Physicists from Tufts have been preparing to study the photoproduction of sigma particles by a high-energy photon beam that is sufficiently slender that photographic emulsions situated only one inch from the axis of the beam may be used to record the tracks of sigma particles emerging from the 1-cm-diameter liquid-hydrogen target. The equipment used includes a lithium hydride hardener, an expecialiy slender and accurately aligned collimation system; several clearing magnets; and a special magnet for deflecting Compton electrons away from the emulsions. By the end of December 1963 all components were in readiness for runs scheduled for January 1964.

7. Pion Production in Peripheral Processes. (D.O.Caldwell et al)

Physicists from M.I.T. and elsewhere are studying the production, by 2 to 5 Bev photons of accurately known energy, of single pions that travel in almost-straight-ahead directions. The purpose is to find the nature of the virtual particle involved in such a photoproduction procese. To provide individual photons of accurately known energy 
the investigators employ a converter to produce electron-positron pairs (from the bremsstrahlung beam from the synchrotron), then cause the positron to strike a thin copper target and emit a high-energy photon in forward direction. By determining the energy of the deflected positron by means of a bending magnet and a 20-channel scintillation hodoscope the investigators can compute the energy of the photon. The direction and momentum of the pion produced when the photon strikes a liquid hydrogen target are evaluated with the aid of four spark chambers, a Scylla-type 48-ton bending magnet, a differential gas-filled Cerenkov counter, and a shower detector. Several trial runs have been made and additional runs are scheduled for the immediate future.

\section{Wide-Angle Pair Production (F. Pipkin et al)}

This group from Harvard and Stanford has been studying the wideangle, 6-Bev, photoproduction of electron-positron pairs, with the object of finding whether the laws of quantum electrodynamics hold at the high energies and short distances involved. Particles produced in a carbon target are analyzed with the aid of a symmetric two-arm spectrometer. Each arm employs a 7-ton focusing magnet of half-quadrupole type, an array of scintillation counters, a $3 \frac{1}{2}$-ton threshold-type gas Cerenkov counter, and other discriminating and detecting devices. Results obtained early in 1963 on photoproduction of pions were analyzed and reported in Phys. Rev. Ietters of Dec. 1, 1963; they support the peripheral model proposed by Drell. During the last few months of 1963 the group obtained much 
CEAL-1009

data on electron pair production, and this work is continuing.

9. Shielding Experiments (CEA Physicists)

Results obtained in experiments on longitudinal and transverse shielding against multi-Bev bremsstrahlung beams by ilmenite-loaded concrete walls 2 to $12 \mathrm{ft}$. thick were analyzed and reported in CEAI1004. Additional experiments, designed to evaluate the effectiveness of such shielding against high-energy neutrons, were performed and have been reported in CEAL-1007.

10. Spark Chamber Studies of Photoproduction (D. H. Frisch et al).

Physicists from M.I.T. will study a wide variety of photoproduction processes with the aid of a large $104 \pi^{\prime \prime}$ spark chamber situated in the field of a specially designed 130-ton magnet. The ( 1 to 5 Bev) photons employed will originate in a fine wire mounted directly in the path of the orbiting electrons at the center of Magnet 12. By measuring the individual photon in coincidence with the recoil electron responsible, and finding the change in energy of this electron, the investigators can compute the energy of the photon. Construction of the main component--the special magnet--is in an advanced stage.

\section{Proton-Compton Effect at 1 to 3 Bev (M.Deutsch et al)}

This group of M.I.T. physicists has been studying the elastic scattering of photons by protons at energies previously unavailable. Their equipment includes a train of spark chambers, scintillation counters, and attenuation plates of aluminum for measuring the direction 
and energy of the recoil proton and a train containing a scintillation counter and a glass Cerenkov counter for measuring the scattered photon. In July 1963 more than 25,000 successful spark-chamber photographs were obtained at energies of 1 to $1.5 \mathrm{Bev}$; the results are now being analyzed. Additional runs, employing energies up to $2.5 \mathrm{Bev}$, are to be made soon.

12. Elastic scattering of Electrons by Deuterons (J.I.Friedman et al)

Physicists from M.I.T. have been preparing to study the rare events in which a high-energy electron strikes a heavy-hydrogen target and is elastically scattered by a deuteron, rather than by a single nucleon. The same target tank and spectrometer used by Wilson et al (see Item I) will be used. The detection equipment will use scintillation counters and also Cerenkov counters to discriminate between deuterons and nucleons. Some orienting runs were made in December, and the main runs are to start in a few months.

13. Positron Scattering Experiment ( $L$. Hand et al)

A group of Harvard physicists is preparing to study the scattering of positrons by protons. Coplanar events are to be analyzed, using spark chambers. The results will permit comparison of electron scattering and positron scattering.

\section{Analysis of Bremsstrahlung Beam (CEA Physicists)}

CEA physicists have designed and procured much of the equipment needed for ditrmining the spectral energy distribution of a multi-Bev photon beam. A 20-ton Orpheus-type pair-spectrometer magnet will be used to divert the 
positrons and electrons produced in a thin converter toward two symmetrically arranged scintillation hodoscopes backed up by glass Cerenkov hodoscopes. It is estimated that an accuracy of $\frac{1}{2}$ to $1 \%$ in enerey of the individual photon will be achieved.

15. Production of polarized High=Energy Photons. (R.H.Milburn et al)

Physicists from Tufts and CEA began preparations for exploring the feasibility of producing linearly polarized high-energy photons. Linearly polarized photons of red light (about $2 \mathrm{ev}$ ) from a ruby laser are to be aimed head-on at a beam of multi-Bev electrons in one straight section of the synchrotron, with the expectation that a small but appreciable fraction of the photons will be scattered almost straight backward with greatly increased energy and with a high degree of polarization. Estimates suggest that about 100 linearly polarized photons having 400 to $850 \mathrm{Mev}$ energy will be produced per pulse of the laser. In the current six-month period most of the necessary design work on the special mechanical components required was completed.

\section{PART III EQUIPRENT AND FACILITIES}

In the current six-month period many new types of equipment were built or purchased and additional facilities were made available to experimentalists. Among the new types of equipment the following may be mentioned: Equipment for permitting momentum matching of linac and synchrotron proper, vacuum chambers of more radiation-resistant type, improved exit-type vacuum chambers, pole-face-winding assemblies of improved mechanical characteristics, mechanically stronger coils for 
the 60-ton inductor of the main magnet power supply, simpler and more reliable cooling system for the coremblocks of this inductor, more versatile master-oscillator for the $\mathrm{rf}$ system and an improved frequency modulation system for increasing the number of electrons captured into stable orbits at injection, system for measuring and correcting for horizontal orbit distortions at injection, coils and power supplies for the beam-bump system of target engagement and a time-sharing system that allots successive bumps to different portions of the ring so that two experiments can be carried on simultaneously.

The design and procurement of special magnets needed by experimentalists was continued; several new magnets were received and others are on order. The equipment for powering the magnets and improving the regulation was obtained, and the distribution system was revised for greater convenience.

Construction of a lot of four new coolers for liquid hydrogen targets was nearly complete. The refrigerator used in conjunction with the 12-inch-diameter liquid-hydrogen-filled bubble chamber was put into operation successfully; an improved heat exchanger was obtained and is to be installed soon. A similar heat exchanger, to be used in the helium Iiquefier in the Cryogenics Room, is on order.

The special magnets and pulsed power supplies required for the routine production of an external electron beam (demonstrated successfully in July 1963 with improvised power supplies) have been procured and are being tested. Construction of a 6-inch-diameter-aperture Faraday cup for appraising and stopping the external electron beam is nearly complete. Two groups of experimentalists have made plans for using the external beam. 
CEAL-1009

Capacitor banks and inductive reactors for correcting the power factor of the electrical loads of the accelerator proper, experimenters ${ }^{\circ}$ magnets, and miscellaneous facilities are on order and are expected to arrive in a few months. Besides effecting a large saving in annual charges for electricity, this equipment will make it possible to operate many large power supplies simultaneously, so that time-sharing of beams and parasiting can be extended.

\section{PART IV ACCELERATOR OPERATION}

Following a seven-week shut-down of accelerator operation in the period from July. 14 through Sept. 4 to permit major repairs and improvements to be made, the accelerator ran well. Typically, the daytime operations shift was devoted to machine improvements and to installing and testing new components, and the evening and night shifts were devoted to routine operation on behalf of the experimentalists.

Further improvements were made during a three-weeks shutdown from Dec. 14, 1963, through Jan. 5, 1964.

In all, nine groups of experimenters (listed in Part II) enjoyed use of high-energy beams.

Many minor difficulties in the linac, rf system, and vacuum chambers arose and were overcome. It still appears that minor improvements made in the linac from time to time will never be really adequate and that a linac of considerably increased energy, stability, and reliability is needed. 


\section{PART V MAJOR IMPROVEMENTS MADE}

In June, July, and August of 1963 all major controls and indicators for the synchrotron as a whole were moved from the temporary control room (Room 103) to the new control room, situated on the ground floor of the Power Building. Efficiency of operation was increased greatly by this change-over.

The new Counting Room, situated above the Target Area, was constructed during the six-month period in question. The earth fill above the Target Area was removed and replaced with a 7-ft layer of ordinary concrete, pig iron, and ilmenite-loaded concrete, which provided ample attenuation of gamma radiation and neutron radiation originating in the Target Area and traveling upward. The new room was then constructed and, by $12 / 31 / 63$, was finished and made ready for occupancy by experimenters.

A retaining wall along the Hammond Street and Gorham Street boundaries of the property was built, and the level of earth fill there was raised in order to provide a greater attenuation of radiation from beam scrapers, etc., within the Circular Tunnel.

A ground-level walk-way from the Laboratory Building to the Power Building was constructed. 


\section{LEGAL NOTICE}

This report was prepared as an account of Government sponsored work. Neither the United States, nor the Commission, nor any person acting on behalf of the. Commission:

A. Makes any warranty or representation, express or implied, with respect to the accuracy, completeness, or usefulness of the information contained in this report, or that the use of any information, apparatus, method, or process disclosed in this report may not infringe privately owned rights or

B. Assumes any liabilities with respect to the use of, or for damages resulting from the use of any information, apparatus, method, or process disclosed in this report.

As used in the above, "person acting on behalf of the Commission" includes any employee or contractor of the Commission to the extent that such employee or contractor prepares, handles or distributes, or provides access to any information pursuant to this employment or contract with the Commission. 